\title{
Epidemiological, Diagnosis, Therapeutic and Evolving Profile of Triple Negative Breast Cancer in Senegal
}

\author{
Papa Macoumba Gaye1,2*, Mouhamed Diouf', Mouhamadou Bachir Ba1, Doudou Diouf ${ }^{2,4}$, \\ Fatimatou Néné Sarr'1, Maimouna Mané1, Mamadou Sarr ${ }^{4}$, Mamadou Moustapha Dieng2,4, \\ Sidy Ka ${ }^{2,4}$, Ahmadou Dem ${ }^{2,3}$ \\ ${ }^{1}$ Radiotherapy Department of Dalal Jamm Hospital, Dakar, Senegal \\ ${ }^{2}$ Cheikh Anta Diop University of Dakar, Dakar, Senegal \\ ${ }^{3}$ Oncological Surgery Department of Dalal Jamm Hospital, Dakar, Senegal \\ ${ }^{4}$ Joliot Curie Institute in Dakar, Aristide Ledantec Hospital, Dakar, Senegal \\ Email: *macoumba.gaye@gmail.com,drmdiouf@gmail.com, mbbachir21@gmail.com, doudougara@hotmail.com, \\ nenesarr92@gmail.com,maimouna.mane@hotmail.com, sarrdou2004@yahoo.fr,mustaphamamadou@gmail.com, \\ sidy.ka@ucad.edu.sn, adehdem@gmail.com
}

How to cite this paper: Gaye, P.M., Diouf, M., Ba, M.B., Diouf, D., Sarr, F.N., Mané, M., Sarr, M., Dieng, M.M., Ka, S. and Dem, A. (2021) Epidemiological, Diagnosis, Therapeutic and Evolving Profile of Triple Negative Breast Cancer in Senegal. Advances in Breast Cancer Research, 10, 100-109.

https://doi.org/10.4236/abcr.2021.103008

Received: June 29, 2021

Accepted: July 20, 2021

Published: July 23, 2021

Copyright (C) 2021 by author(s) and Scientific Research Publishing Inc. This work is licensed under the Creative Commons Attribution International License (CC BY 4.0).

http://creativecommons.org/licenses/by/4.0/

\begin{abstract}
Objective: Describe the epidemiological, diagnostic, therapeutic and evolutionary profile of triple negative breast cancer at the Dakar Cancer Institute in Senegal. Patients and Methods: This was a retrospective study between January 1, 2011 and December 31, 2014. All patients with a triple negative molecular profile were included. The data were collected from the medical records of the patients. The data were entered and analyzed with SPSS edition 16 software under Windows 7. Results: Two hundred and twenty-five patients were selected. The mean age was $47.9 \pm 12.5$ years with extremes of 25 and 90 years. The main reason for consultation was dominated by the finding of a breast lump. The mean clinical tumor size was $8,54 \mathrm{~cm}$ with a large majority of T3-T4 tumors $26 \%$ and $63 \%$ respectively, lymph node involvement in one hundred and seventy-two cases (76.4\%); twenty eight patients (12.4\%) were metastatic from the outset. Non-specific invasive carcinoma was the most common histologic type (78.2\%), and more than half of the patients $(53.3 \%)$ had an aggressive tumor (Scarff-Bloom-Richardson grading III). Neoadjuvant chemotherapy was performed in $65.78 \%$ of cases. We noted $27.7 \%$ total response and $41.7 \%$ partial response in patients who have received this neoadjuvant chemotherapy. The surgery was radical in $77 \%$ of cases, conservative in $14 \%$ and cleanliness surgery for palliative purposes in $9 \%$ of cases. Adjuvant radiotherapy is performed in $58.6 \%$ of operated patients. The mean time to follow-up was 20.63 months with extremes of 1 and 53 months. Overall
\end{abstract}


survival was $69.8 \%$ at one year, $41.6 \%$ at two years and $25.6 \%$ at three years. Conclusion: The descriptive analysis of these results confirms the high frequency of triple-negative breast cancer in Senegal and its poor prognosis.

\section{Keywords}

Breast Cancer, Triple Negative, Senegal

\section{Introduction}

Breast cancer is the first cancer in the world in terms of incidence and the fourth in terms of mortality [1]. Statistically, it is estimated that 1 in 11 women will develop breast cancer in her lifetime [2]. In Senegal, it is respectively the second (16.1\%) and third cancer in terms of incidence and mortality [3]. A new taxonomy of breast cancer establishes five basic tumor genotypes including the triple negative phenotype. These triple negative breast cancers (TNBCs) are defined by the negativity of estrogen receptors (ER), progesterone receptors (PR) and human epidermal growth factor receptor (HER-2). This tumor subtype, by definition not accessible to targeted therapies such as hormone therapy and Herceptin, poses a real problem of care [4]. These TNBCs have high metastatic potential and poor survival compared to other subtypes [5]. In Senegal, in the last decade, the development of laboratories capable of carrying out molecular profiles of breast cancers has enabled us to carry out this study, the aim of which is to describe the main epidemiological, diagnostic, therapeutic and evolutionary aspects of TNBCs at the Dakar Cancer Institute.

\section{Patients and Methods}

This is a descriptive retrospective study of the files of two hundred and twenty-five patients treated at the Dakar Cancer Institute for triple negative breast cancer between January 2011 and December 2014. The epidemiological, diagnostic, therapeutic and evolutionary information has been obtained. Were included, patients who presented with the following characteristics:

- Have a medical file including epidemiological data (risk factors, age, sex, menarche, age of 1st pregnancy, concept of taking contraceptives or not, pregnancy and parity, history family cancer), and clinical (time and reason for consultation, average tumor size, TNM classification);

- Have had a tumor biopsy before treatment;

- Have a histological type and the histopronostic grade of Scarff-Bloom-Richardson (SBR);

- Be of triple negative molecular profile (Figure 1);

- Contain information on the treatment and the fate of the patient.

The samples were analyzed in various anatomopathological laboratories in

Dakar and abroad (France). A percentage of hormone receptor labeling of more 


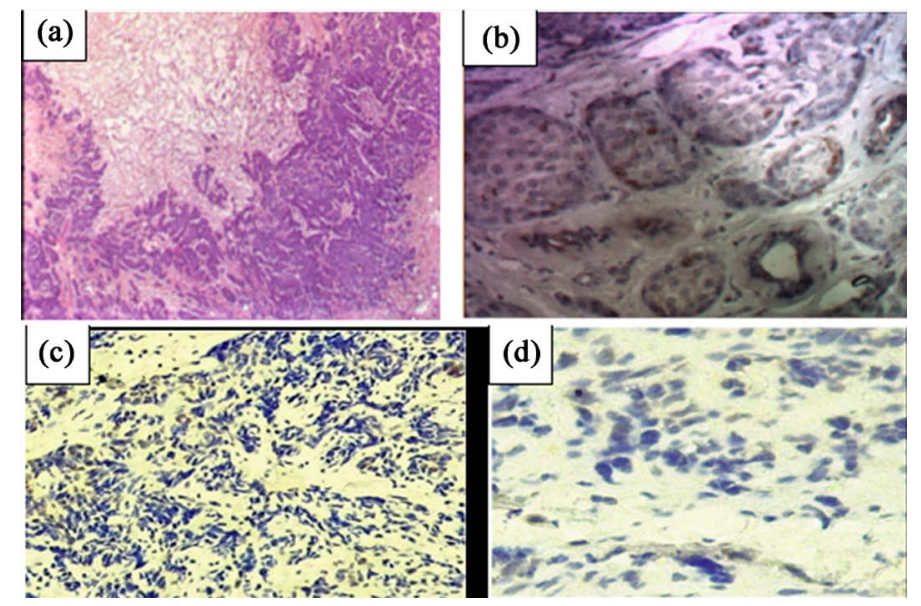

Figure 1. Histo-immunohistochemical characteristics of TNBC/basal like. (a) Histology of infiltrating duct carcinoma with necrosis and central intratumoral fibrosis. (b) Immumohistochemical analysis showing low positivity of ER, less than $5 \%$ of tumor cells. (c) Immumohistochemical analysis showing low positivity of PR, less than $5 \%$ of tumor cells. (d) Immunohistochemical analysis showing an absence of Her-2 positivity in tumor cells.

than $10 \%$ of the tumor cells was considered positive. HER2/neu expression was assessed and fluorescent in situ hybridization (FISH) was indicated in ambiguous cases (HER2 2+). Tumors with a Ki67 greater than 15\% were considered proliferative. The degree of tumor differentiation is assessed by the modified SBR grade of Elstone and Ellis. Paucity parity was defined as a parity between 1 to 4 and multiparity from five deliveries.

We used the TNM classification of the UICC (International Union against Cancer) 7th edition established in 2010.

The response rates to neoadjuvant chemotherapy were evaluated on the extent of tumor regression on clinical examination (before the first cycle of chemotherapy, after the third and at the end of chemotherapy) and according to RECIST criteria [6].

We considered as local recurrence the new tumors located less than $3 \mathrm{~cm}$ from the initial bed, presenting the same histology and occurring more than 6 months after surgical treatment. Overall survival is defined as the time between the date of initial diagnosis and the date of death or the date of breaking news.

The data were collected, and analyzed with SPSS edition 16 software under Windows 7. Overall survival was calculated according to Kaplan-Meier and a relationship was considered significant when the p-value is less than 0.05 .

\section{Results}

During the study period, one thousand two hundred fifty-three patients were treated for breast cancer at the Dakar Cancer Institute. Among them, five hundred nineteen cases had benefited from immunohistochemistry $(41.4 \%$ of all cases observed), of which two hundred and twenty-five (43.35\%) were categorized as triple negative, one hundred and forty-five (27.93\%) were luminal A, thirty three patients $(6.35 \%)$ luminal B, sixty $(11.56 \%)$ were HER 2 positive and 
fifty six patients (10.78\%) with an unspecified HER 2 status. Concerning the "triple negative" patients, the average age was $47.9 \pm 12.5$ years with extremes of 25 and 90 years. The age group most represented was that of $40-50$ years (29.8\%). The main epidemiological aspects of the patients are summarized in Table 1.

The mean time to consultation was 7.3 months and $39.1 \%$ of cases had consulted within 6 months of the onset of the first symptoms. The mean clinical tumor size was $8.54 \mathrm{~cm}$ with extremes of 2 and $20 \mathrm{~cm}$. The main clinical, paraclinical and histopathological data of the patients in our series are summarized in Table 2.

From a therapeutic standpoint, neoadjuvant chemotherapy was carried out in one hundred forty eight patients (65.78\%), of which $98 \%$ in the form of poly-chemotherapy and $2 \%$ in the form of mono-chemotherapy. We noted $27.7 \%$ total response and $41.7 \%$ partial response. The complete response was mainly observed with the sequential protocols FEC + Docetaxel (60\%) and AC60 + Docetaxel (58.3\%). One hundred and sixty-two patients had surgery. The trend was most often radical, given the advanced stage of the disease: $77 \%$ of patients had undergone a modified Patey-type mastectomy, 14\% of them a conservative treatment and $9 \%$ a clean palliative mastectomy. The surgical excision margins were invaded in eight patients (4.9\%). Tumor emboli were present in thirty six patients $(22.2 \%)$. For eighteen patients (11.2\%) there was complete tumor sterilization after chemotherapy. Axillary dissection was positive for sixty three patients (38.9\%), including $17.9 \%$ with capsular breakage. Sixty operated patients had received adjuvant chemotherapy. It consisted of poly-chemotherapy for fifty

Table 1. Epidemiological characteristics of the patients in our series.

\begin{tabular}{lcc}
\hline \multicolumn{1}{c}{ Settings } & Effective & Percent $(\%)$ \\
\hline Age & 13 & \\
$>30$ years & 44 & 5.77 \\
$30-40$ & 67 & 19.55 \\
$40-50$ & 56 & 29.77 \\
$50-60$ & 45 & 24.88 \\
$<60$ years & & 20 \\
Menopause & 127 & \\
Yes & 98 & 56.44 \\
No & & 43.55 \\
Parity & 31 & \\
Nulliparous & 21 & 13.77 \\
Pauciparous & 173 & 9.33 \\
Multiparous & & 76.88 \\
Family history of breast cancer & 37 & \\
Yes & 188 & 83.55 \\
No & & \\
\hline
\end{tabular}


Table 2. Clinical, paraclinical and histo-immunohistochemical characteristics of the patients in our series.

\begin{tabular}{|c|c|c|}
\hline Settings & Effective & Percent (\%) \\
\hline \multicolumn{3}{|l|}{ Reason for consultation } \\
\hline Breast nodule & 181 & 80.44 \\
\hline Flow & 21 & 9.33 \\
\hline Mastodynia & 23 & 10.23 \\
\hline \multicolumn{3}{|l|}{ TNM classification } \\
\hline$-\mathrm{Tx} / \mathrm{T} 1 / \mathrm{T} 2 / \mathrm{T} 3 / \mathrm{T} 4$ & $5 / 4 / 15 / 59 / 142$ & $2.2 / 1.8 / 7 / 26 / 63$ \\
\hline$-\mathrm{Nx} / \mathrm{N} 0 / \mathrm{N}+$ & $12 / 41 / 172$ & $5.4 / 18.2 / 76.4$ \\
\hline$-\mathrm{M}+$ & 28 & 12.44 \\
\hline \multicolumn{3}{|l|}{ Histological type } \\
\hline Infiltrating duct carcinoma (IDC) & 176 & 78.20 \\
\hline Infiltrating lobular carcinoma (ILI) & 4 & 1.8 \\
\hline IDC + Carcinoma in situ (CIC) & 14 & 6.2 \\
\hline Medullary carcinoma & 4 & 1.8 \\
\hline Metaplastic carcinoma & 19 & 8.4 \\
\hline Papillary carcinoma & 4 & 1.8 \\
\hline Undifferentiated carcinoma & 4 & 1.8 \\
\hline \multicolumn{3}{|l|}{ SBR grade } \\
\hline Grade I & 4 & 1.8 \\
\hline Grade II & 70 & 31.11 \\
\hline Grade III & 120 & 53.33 \\
\hline Grade Not specified & 31 & 13.77 \\
\hline \multicolumn{3}{|l|}{ Classification by stages } \\
\hline Stage I & 8 & 3.6 \\
\hline Stage II & 30 & 13.3 \\
\hline Stage III & 158 & 70.2 \\
\hline Stage IV & 24 & 10.7 \\
\hline Stage Not specified & 5 & 2.2 \\
\hline
\end{tabular}

six patients and mono-chemotherapy for four patients. Ninety-five operated patients (58.6\%) had received adjuvant radiotherapy.

From an evolutionary point of view, the rate of locoregional recurrence in our series was $12.9 \%$ with a mean delay of 10.13 months. Twenty-one percent of recurrences occurred at 6 months. Fifty-two patients (23.1\%) presented with metachronous metastases. The mean time to onset of these metastases was 17.52 months. Ninety-nine percent of metastases occurred within the first 2 years. The mean time to follow-up was 20.63 months with extremes of 1 and 53 months. Seventy-five patients (33.4\%) were alive including fifty-eight without progressive disease, seventy six patients (33.6\%) had died including and finally seventy three patients $(33 \%)$ were lost to follow-up including thirty six with progressive disease. Overall survival was $69.8 \%$ at one year, $41.6 \%$ at two years and $25.6 \%$ at three years (Figure 2). The factors found which influenced the overall survival 
were the initial tumor stage and the response to chemotherapy $(\mathrm{p}<0.01)$ (Figure 3, Figure 4).

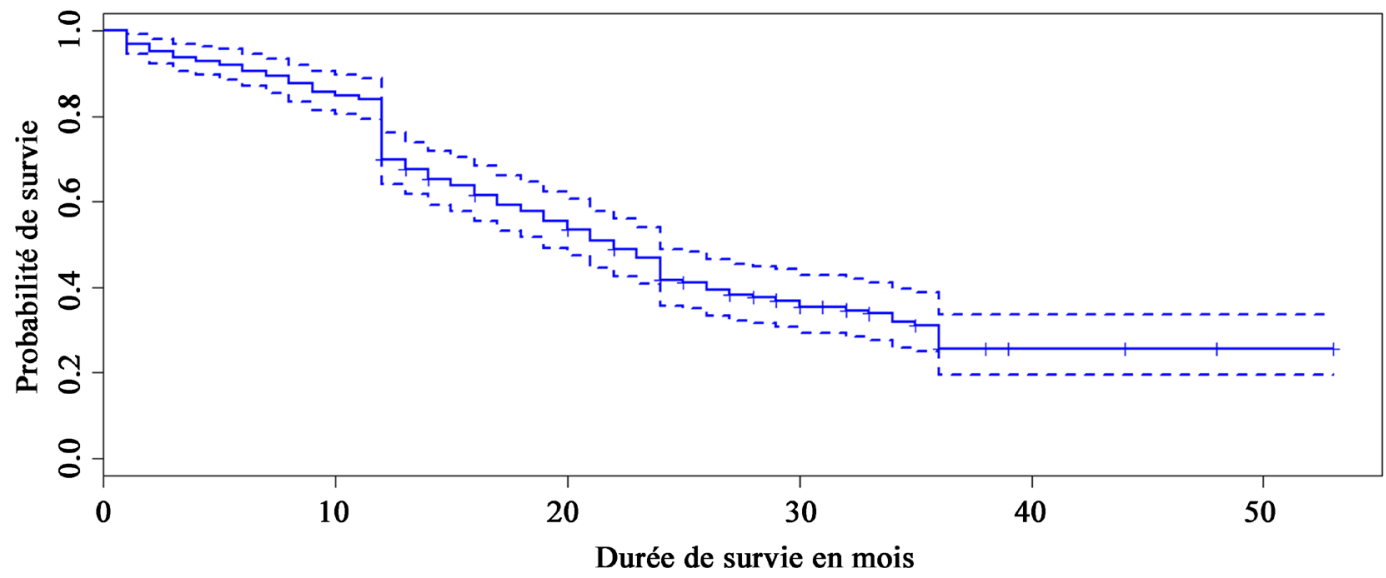

Figure 2. Overall survival curve in our series.

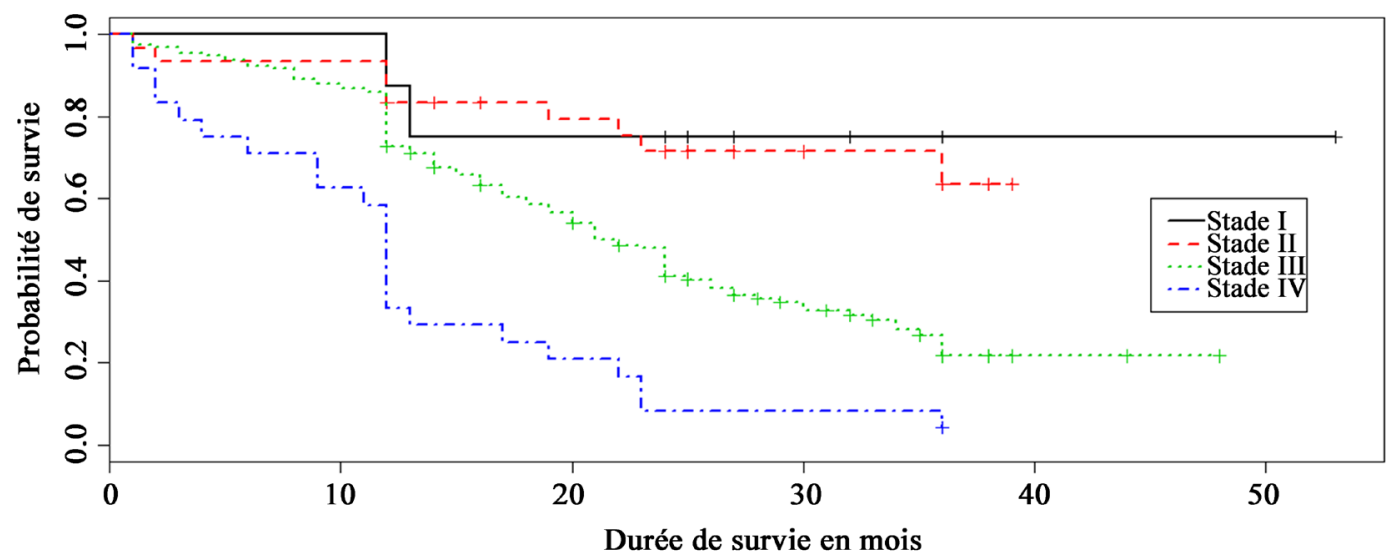

Figure 3. Overall survival curve according to the initial tumor stage.

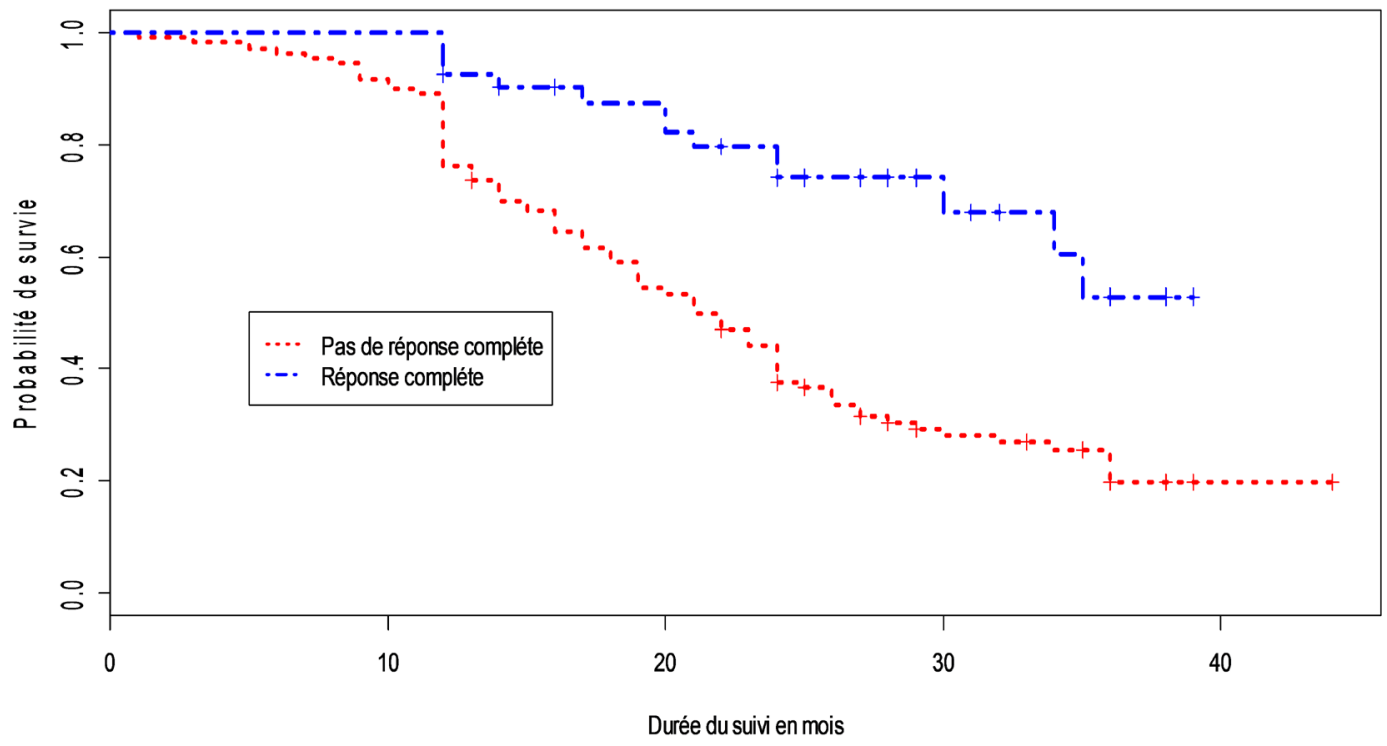

Figure 4. Overall survival curve according to the complete response to neoadjuvant chemotherapy. 


\section{Discussion}

The incidence of breast cancer has continued to increase worldwide even if mortality remains stable due to innovative therapies [1]. It is a heterogeneous disease that brings together several entities with different morphological, molecular and functional characteristics. TNBCs account for around $10 \%-20 \%$ of all breast cancers [7]. In Africa its incidence is high; it is particularly in Mali and Nigeria, $46 \%$ and 55\% [8] [9]. In our series, it represented the most frequent molecular form (43.35\%). In the West, large-scale studies found an incidence of $14 \%$ in the United States and $16.3 \%$ in Great Britain [10] [11]. This difference is probably underestimated because the rate of carrying out immunohistochemistry is still low in the continent; it was $41.4 \%$ in our series.

The age pyramid shows that our patients are 10 to 20 years younger than patients in Europe and the USA in which more than half of the cases occur around 65 years old and the average age at diagnosis is around 60 years old [10] [12] [13].

Clinically, these cancers are characterized by larger size at diagnosis and more frequent lymph node involvement [8] [11]. In our series the mean height was 8.4 $\mathrm{cm}$, the vast majority of patients were classified T3, T4 (89.33\%) and $76.1 \%$ of cases had lymph node involvement.

The anatomo-pathological analysis of triple-negative cancers has shown that they are divided into various histological types in the general population [14]. In our series, 7 subtypes were found, the most frequent of which was invasive carcinoma of the nonspecific type (78.2\%). They are characterized by a higher histological grade, a large number of mitoses, insufficient stromal content, central necrosis pushing the limits of invasion, a stromal lymphocyte response and multiple apoptotic cells [15]. It is usually reported, as in our series, a majority of undifferentiated forms, with nuclear atypia and high mitotic indices [11] [12] [16].

Therapeutically, in the absence of a target, chemotherapy is the only approved systemic treatment that improves outcomes in triple negative cancers [17]. Relative chemosensitivity is linked to the often-undifferentiated nature and high mitotic index of these tumors. Anthracycline/Taxane-based treatment regimens have been shown to be active in TNBCs [18]. This treatment allowed us to note $27.7 \%$ total response and $41.7 \%$ partial response. Liedtke et al. [17] had shown, in neoadjuvant, a complete histological response rate (PCR) of $22 \%$ in TNBCs, versus $11 \%$ in the non-TNBC group. This complete response rate was $11.2 \%$ in our study. The place of other cytotoxics and targeted treatments remains to be determined [18]. In the event of metastatic relapse, treatment options are rare due to the absence of a target (hormone receptors and HER2). However, immunotherapy has experienced significant development in recent years [19]. The surgical indications for triple-negative cancers are similar to those for other invasive breast cancers [20]. The use of radiotherapy is systematic after conservative treatment and after mastectomy it remains indicated in T3, T4 and some pT1, pT2 tumors with poor prognostic factors [21]. 
TNBCs are associated with a high risk of metastasis and death, mainly during the first 3 to 5 years of follow-up [7] [17] [22]. In our series $23.1 \%$ of metachronous metastases were noted with a mean time to onset of 17.52 months and seventy six patients (33.7\%) died after a mean follow-up of 20.63 months (1 - 53 months). The 3 -year overall survival was $25.6 \%$. This overall survival rate was lower than those of the main studies on TNBCs, in particular that of Liedtke et al. [17] which was $74 \%$ at 3 years versus $89 \%$ for non-TNBCs. This low 3 -year survival rate can be explained by several factors including the locally advanced stages of our patients, a suboptimal use of adjuvant chemotherapy, the cobalt radiotherapy technique used and a large number of patients lost to follow-up.

The main limitation of this study remains its retrospective nature with its procession of incomplete files and patients lost to follow-up.

\section{Conclusion}

The descriptive analysis of its results confirms a high frequency of triple-negative breast cancer in Senegal and their unfavorable prognosis. It constitutes a real challenge in the management of breast cancer due to the absence of therapeutic targets. Recent advances in the understanding of signaling pathways in this tumor subtype and data from targeted therapy offer hope for better management of patients with this breast cancer.

\section{Conflicts of Interest}

The authors declare no conflicts of interest regarding the publication of this paper.

\section{References}

[1] Sung, H., Ferlay, J., Siegel, R.L., Laversanne, M., Soerjomataram, I., Jemal, A., et al. (2021) Global Cancer Statistics 2020: GLOBOCAN Estimates of Incidence and Mortality Worldwide for 36 Cancers in 185 Countries. CA: A Cancer Journal for Clinicians, 71, 209-249. https://doi.org/10.3322/caac.21660

[2] Ji, P., Gong, Y., Jin, M.L., Hu, X., Di, G.H. and Shao, Z.M. (2020) The Burden and Trends of Breast Cancer from 1990 to 2017 at the Global, Regional, and National Levels: Results from the Global Burden of Disease Study 2017. Frontiers in Oncolo$g y$, 10, 650. https://doi.org/10.3389/fonc.2020.00650

[3] Globocan 2020 Senegal-Google Search [Internet]. https://www.google.com/search?q=globocan+2020+s\%C3\%A9n\%C3\%A9gal\&rlz=1 C1CHBD frGB878TN878\&oq=globocan $+2020+$ s\%C3\%A9n\%C3\%A9gal\&aqs=chro me..69i57.17373j0j15\&sourceid $=$ chrome $\&$ ie $=U$ UTF-8

[4] Nagini, S. (2017) Breast Cancer: Current Molecular Therapeutic Targets and New Players. Anti-Cancer Agents in Medicinal Chemistry, 17, 152-163. https://doi.org/10.2174/1871520616666160502122724

[5] Lehmann, B.D., Bauer, J.A., Chen, X., Sanders, M.E., Chakravarthy, A.B., Shyr, Y., et al. (2011) Identification of Human Triple-Negative Breast Cancer Subtypes and Preclinical Models for Selection of Targeted Therapies. Journal of Clinical Investigation, 121, 2750-2767. https://doi.org/10.1172/JCI45014 
[6] Taieb, S., Penel, N., Bonodeau, F. and Ceugnart, L. (2009) New Version of the Criteria Recist: Practical Aspects and Limits of Morphological Imagery. Journal de Radiologie, 90, 1210-1211. https://doi.org/10.1016/S0221-0363(09)74864-4

[7] Boyle, P. (2012) Triple-Negative Breast Cancer: Epidemiological Considerations and Recommendations. Annals of Oncology, 23, vi7-vi12. https://doi.org/10.1093/annonc/mds187

[8] Ly, M. (2011) Study of the Epidemiological and Biological Characteristics of Breast Cancer in the Bamako Region (Mali). PhD Thesis, Paris, 6.

[9] Huo, D., Ikpatt, F., Khramtsov, A., Dangou, J.M., Nanda, R., Dignam, J., et al. (2009) Population Differences in Breast Cancer: Survey in Indigenous African Women Reveals Over-Representation of Triple-Negative Breast Cancer. Journal of Clinical Oncology, 27, 4515-4521. https://doi.org/10.1200/JCO.2008.19.6873

[10] Bauer, K.R., Brown, M., Cress, R.D., Parise, C.A. and Caggiano, V. (2007) Descriptive Analysis of Estrogen Receptor (ER)-Negative, Progesterone Receptor (PR)-Negative, and HER2-Negative Invasive Breast Cancer, the So-Called Triple-Negative Phenotype: A Population-Based Study from the California Cancer Registry. Cancer, 109, 1721-1728. https://doi.org/10.1002/cncr.22618

[11] Rakha, E.A., Putti, T.C., Abd El-Rehim, D.M., Paish, C., Green, A.R., Powe, D.G., et al. (2006) Morphological and Immunophenotypic Analysis of Breast Carcinomas with Basal and Myoepithelial Differentiation. The Journal of Pathology, 208, 495-506. https://doi.org/10.1002/path.1916

[12] Dent, R., Trudeau, M., Pritchard, K.I., Hanna, W.M., Kahn, H.K., Sawka, C.A., et al. (2007) Triple-Negative Breast Cancer: Clinical Features and Patterns of Recurrence. Clinical Cancer Research, 13, 4429-4434. https://doi.org/10.1158/1078-0432.CCR-06-3045

[13] Hasan, A. and Youssef, A. (2021) Infiltrating Duct Carcinoma of the Breast; Histological Difference between the Primary and the Axillary Nodal Metastasis. Revista de Senología y Patología Mamaria, 34, 17-22. https://doi.org/10.1016/j.senol.2020.09.003

[14] Boisserie-Lacroix, M., MacGrogan, G., Debled, M., Ferron, S., Lippa, N. and Hurtevent-Labrot, G. (2014) Triple-Negative Breast Cancer. The Triple-Negative Is Frequent in Mutated Patients: How Not to Miss It? How to Characterize It? More Generally, Can Imaging Guide Histological Diagnosis? Imag Woman, 24, 105-112.

[15] Irvin Jr., W.J. and Carey, L.A. (2008) What Is Triple-Negative Breast Cancer? European Journal of Cancer, 44, 2799-2805. https://doi.org/10.1016/j.ejca.2008.09.034

[16] Schneider, B.P., Winer, E.P., Foulkes, W.D., Garber, J., Peru, C.M., Richardson, A., et al. (2008) Triple-Negative Breast Cancer: Risk Factors to Potential Targets. Clinical Cancer Research, 14, 8010-8018.

https://doi.org/10.1158/1078-0432.CCR-08-1208

[17] Liedtke, C., Mazouni, C., Hess, K.R., André, F., Tordai, A., Mejia, J.A., et al. (2008) Response to Neoadjuvant Therapy and Long-Term Survival in Patients with Triple Negative Breast Cancer. Journal of Clinical Oncology, 26, 1275-1281.

https://doi.org/10.1200/JCO.2007.14.4147

[18] Kumar, P. and Aggarwal, R. (2016) An Overview of Triple-Negative Breast Cancer. Archives of Gynecology and Obstetrics, 293, 247-269. https://doi.org/10.1007/s00404-015-3859-y

[19] Mittendorf, E.A., Philips, A.V., Meric-Bernstam, F., Qiao, N., Wu, Y., Harrington, S., et al. (2014) PD-L1 Expression in Triple-Negative Breast Cancer. Cancer Immunology Research, 2, 361-370. https://doi.org/10.1158/2326-6066.CIR-13-0127 
[20] Chauvet, M.P. (2019) New Breast Cancer Surgery. La Presse Médicale, 48, 1123-1130. https://doi.org/10.1016/j.lpm.2019.08.020

[21] Hennequin, C., Barillot, I., Azria, D., Belkacémi, Y., Bollet, M., Chauvet, B., et al. (2016) Radiotherapy for Breast Cancer. Cancerl Radiotherapy, 20, S139-S146. https://doi.org/10.1016/j.canrad.2016.07.025

[22] Dieras, V., Tresca, P., Le Tourneau, C., Salomon, A.V. and Pierga, J.Y. (2010) Triple Negative Breast Cancers. Lett Oncologist, 19, 349-354. 